\section{La salud de las poblaciones olvidadas de América Latina}

En las zonas tropicales y subtropicales de América Latina, se combinan de forma inusitada la pobreza, la enfermedad y el subdesarrollo. La carga de enfermedad consiste principalmente en infecciones parasitarias intestinales, enfermedad de Chagas, dengue, malaria y otras fácilmente transmisibles y por lo general evitables. Por su limitación geográfica, estas dolencias han existido por siglos en los mismos lugares impidiendo que se formen sociedades capaces de competir en este mundo cada vez más globalizado.

En su artículo reciente de tipo comentario, cuatro autores latinoamericanos deploran que haya habido tan larga demora en la integración de políticas de salud pública, programas y estrategias de bajo costo para mejorar la salud de esas poblaciones olvidadas. Más bien les parece que el resto del mundo simplemente ha aceptado que la enfermedad y el sufrimiento sean parte del subdesarrollo. Por cierto, son más de mil millones las personas que viven con un mínimo de alimento y de leche materna, agua sucia y casi ninguna oportunidad de educación y empleo, lo que que trae como consecuencia la falta de salud.

En la situación que analizan los comentaristas, esos pueblos están muy lejos del ambiente donde se expresan los principios éticos y morales de la Declaración Universal de Derechos Humanos. Su existencia transcurre como una lucha en las zonas marginadas de grandes ciudades, remotas zonas rurales o villas miseria improvisadas de materiales desechados. No solo viven en la indigencia, sino que anualmente millones mueren antes de tiempo como culminación del ciclo vicioso de pobreza, enfermedad y subdesarrollo. En la historia de la humanidad, los microbios han tenido una profunda influencia como agentes de selección natural que atacan a los que viven en condiciones de hacinamiento y falta de higiene. Más de $95 \%$ de las muertes por enfermedades infecciosas ocurren en el mundo en desarrollo, muchas causan desnutrición y esto a su vez acarrea de nuevo el riesgo de infección. Muchas de esas enfermedades han sido soslayadas $\mathrm{u}$ olvidadas por los organismos de salud pública, la industria farmacéutica y los gobiernos. No se ha invertido mucho en investigar fármacos contra las dolencias que más afectan a los pobres, ya que no hay rentas públicas asignadas para esos fines. A menudo no se incluyen entre las prioridades y los programas de lucha se consideran insostenibles.

Desde la Cumbre Mundial de Rio de Janeiro, las Metas de Desarrollo del Milenio constituyen un marco esencial en el que la comunidad internacional puede encarar vigorosamente el reto de preve- nir, controlar y eliminar el hambre y las enfermedades. Es preciso emplear nuevos métodos con recursos existentes para asegurar el éxito de estrategias aceptables para las comunidades enfocadas. El antiguo e ineficiente enfoque vertical tiene que descartarse para dar paso a uno holístico, es decir interprogramático e interinstitucional. El ataque debe empezar combatiendo las fuerzas sociales, económicas y ambientales que propician la manifestación de enfermedades de la pobreza.

La innovación en métodos tiene en cuenta que la pobreza es la fuerza motriz de la enfermedad y el subdesarrollo, y que la participación de la comunidad es una estrategia de avanzada. El paradigma cambia de uno centrado en la enfermedad a otro centrado en la salud de la población. Se trata de combinar todos los programas de control de enfermedades con la participación de diversos sectores (gobierno, comercio, sociedad civil y otros) para llegar a las causas de las enfermedades locales. Es fundamental examinar cuáles son las estructuras sociales que contribuyen a la enfermedad. Cuando los niños sanos y nutridos asisten a la escuela, aprenden más fácilmente y se convierten en adultos productivos capaces de contribuir al crecimiento económico y desarrollo de sus comunidades. Los programas básicos integrados para los niños pueden incluir tratamiento colectivo contra los parásitos, distribución de mosquiteros, instrucciones para protegerse contra el dengue, promoción de la asistencia a la escuela primaria, y programas de agua limpia y de vacunación. Así se beneficia a las familias enteras.

Innumerables barreras se yerguen para impedirlo, por lo que se requiere mucho esfuerzo e investigaciones operativas para evaluar su impacto potencial local, nacional y regional. Para producir resultados sostenibles, la Organización Panamericana de la Salud está presta a colaborar con los sectores nacionales de los estados miembros $\mathrm{y}$, sobre todo, con la gente de las comunidades que sufren. (Franco-Paredes F, Jones D, Rodríguez-Morales AJ, Santos Preciado JI. Commentary: improving the health of neglected populations in Latin America. BMC Public Health.2007;7:11.)

\section{Nuestras comunidades bacterianas internas}

$\mathrm{Al}$ nacer, entramos por primera vez en contacto con millones de bacterias que habitan en la vía del parto. La mayor parte son inofensivas y se instalan inmediatamente en nuestra piel y tubo digestivo. Esas bacterias, que forman complejas comunidades en el organismo de todo recién nacido, contribuyen a nuestro bienestar. Nuestros microbios desempeñan un papel de suma importancia en la di- 
gestión de los alimentos, el metabolismo de medicamentos y el mantenimiento de la salud en general.

De hecho, en cada organismo humano hay 10 veces tantas células microbianas como humanas. Jeffrey Gordon, microbiólogo de la Universidad Washington en St. Louis, declara que nuestro componente microbiano está muy evolucionado y ha aprendido a adaptarse a la vida con nosotros. Hoy día, nuestras comunidades bacterianas son de sumo interés para los investigadores que se esfuerzan por conocer tanto la salud como las enfermedades, especialmente las que no se pueden diagnosticar claramente o tratarse con eficacia. Las nuevas técnicas de laboratorio nos han permitido conocer más de cerca a esos invisibles inquilinos y varios grupos de científicos ya han informado que cualquier interferencia disruptiva tiene consecuencias negativas para nuestra salud, p. ej., obesidad, enteropatía inflamatoria e infecciones vaginales y de las encías. En realidad, los científicos reconocieron su importancia hace tiempo.

Ya en el siglo XIX, Louis Pasteur sabía que perjudicar nuestras bacterias normales causaba enfermedad. Sin embargo, hasta hace poco era difícil estudiarlas, porque la mayoría no se pueden cultivar en el laboratorio. Ahora se puede extraer ADN de una muestra e identificar rápidamente miles de especies bacterianas sin cultivar ninguna. Los estudios más recientes indican que los microbios trabajan juntos en comunidad para influenciar la salud, hallazgo que seguramente tendrá un gran impacto sobre nuestro conocimiento de lo que es enfermedad. David Relman, investigador de enfermedades infecciosas de la Universidad de Stanford, dice que en vez de pensar en la enfermedad como la ausencia o presencia de un solo agente patógeno, debemos pensar en la colectividad.

Por su parte, Jeffrey Gordon, explica que el intestino está lleno de microbios que interactúan entre sí y con el huésped para beneficio de todos. Gordon y su grupo transplantaron comunidades microbianas intestinales de ratones normales a ratones criados en un ambiente estéril, los cuales pronto comenzaron a acumular grasa en sus tejidos. En ellos se había suprimido el factor que regula el almacenaje de energía. Seguidamente compararon la microbiota de ratones obesos y delgados y se sorprendieron de encontrar una gran diferencia entre los dos tipos de bacteria que normalmente habitan el intestino. Los que se crían para ser obesos tienen una mayor proporción de cierto tipo de bacterias y viceversa. $\mathrm{Al}$ transferir microbios de ratones obesos y delgados a ratones exentos de microbios, los primeros engordaron marcadamente. El grupo estudió por un año dos pequeños grupos de personas sometidas a dieta $\mathrm{y}$ en ellos aumentaron las bacterias "de enflaquecimiento" y disminuyeron las de gordura.
A raíz de esos interesantes descubrimientos, se han empezado muchos nuevos estudios. En las microbiotas de personas con enfermedad de Crohn se encontró un mayor número de Escherichia coli y Pseudomonas que en personas con colitis ulcerosa o sanas. También se ha descubierto que las comunidades microbianas afectan no solo al intestino sino a otras partes del organismo y se está investigando el síndrome de vaginosis bacteriana, infección que se encuentra en $10 \%$ a $20 \%$ de las mujeres de los Estados Unidos. En este caso se identificaron 35 especies asociadas con el síndrome, la mitad de ellas desconocidas hasta entonces. El microbiólogo David Fredricks opina que las causantes de la vaginosis son metabólicamente interdependientes y actúan en comunidad, sin poder existir independientemente.

En estudios de trastornos dermatológicos se siguen descubriendo cientos de nuevas bacterias que varían de una persona a otra y aun de una parte del mismo cuerpo a otra. Todas estas observaciones muestran la complejidad de crear agentes terapéuticos frente al número tan grande de miembros interactivos en las comunidades bacterianas. Sin embargo, los adelantos en la tecnología para secuenciar el ADN y en informática permiten abrigar la esperanza de que la tarea de conocer nuestras bacterias y entender su función en la salud y las enfermedades tenga algún día aplicaciones prácticas de beneficio para el ser humano. (Goho A. Our microbes, ourselves. Science News. 2007;171:314-316.)

\section{Frecuencia de los síntomas de menopausia $y$ riesgos asociados en Ecuador}

Mientras más temprano comienzan los síntomas de la menopausia, más tiempo está la mujer expuesta a los efectos negativos de la falta de estrógeno, responsable de cambios fisiológicos y psicológicos que afectan a su calidad de vida. La edad media de presentación de la menopausia en las mujeres ecuatorianas, como en otros países de América Latina, ocurre antes que en las mujeres estadounidenses y europeas, hecho que se ha asociado, entre otros factores, con la mayor altitud en que viven y su menor nivel educacional y socioeconómico.

En este trabajo se analiza la frecuencia de los síntomas de menopausia y los riesgos relacionados en una población de mujeres postmenopáusicas de Ecuador que participaron en un programa de tamizaje metabólico.

En este estudio transversal participaron 325 mujeres postmenopáusicas ( $>1$ año de amenorrea), de 55,9 \pm 8,1 años de edad (mediana: 54 años), que tenían útero y no habían empleado ninguna terapia de sustitución hormonal. Después de un ayuno nocturno, se tomo una muestra de sangre para 